\title{
Development of a Module to Teach Basic Concepts of Interfacing and Con- nectivity in Internet of Things
}

\author{
Prof. Lawrence O Kehinde P.E., Obafemi Awolowo University, Ile-Ife, Osun State, Nigeria
}

Professor Lawrence Kunle Kehinde, a former Engineering Dean and University Deputy Vice Chancellor, received his B.Sc 1st class Hons in Electronics (1971), and a D.Phil, Control Engineering (1975), at the University of Sussex UK. He had his Post Doctoral Studies in Nuclear Instrumentation at University of California, Berkeley USA (1977-1978) as an IAEA Fellow. He has spent most of his years as a Professor of Instrumentation Engineering at the Obafemi Awolowo University (OAU), Ile-Ife, Nigeria. He was the Rector of the first private Polytechnic in Nigeria. He recently concluded a 3-year Visiting Professor term at the Texas Southern University, Houston Texas USA. He has worked in Techno-Managerial position as the Director of ICT at OAU for years. His major field is Instrumentation Designs and has designed equipment, two of which had received British patents in the past. He was the founding Principal Investigator of the University's iLab research and he currently designs remote and virtual experiments for remote experimentation. He is a Chartered Engineer, a Fellow of the Computer Professional Nigeria and a member of IEEE and ASEE.

\section{Mr. Obasegun Tekena Ayodele, IEEE Educational Activities}

Obasegun Tekena Ayodele is a student researcher in the Department of Electronic and Electrical Engineering, Obafemi Awolowo University, Ile-Ife, Nigeria. His previous researches spans across VLSI design for processors and dsp chips. His current research interest is in new teaching paradigms with Remote Labs. He focuses on defining approaches for designing realistic and engaging remote labs.

Mr. Olubiyi Olaoluwa Akintade, Department of Electronic \& Electrical Engineering, Obafemi Awolowo University, Ile-Ife, Nigeria.

Olubiyi Olaoluwa Akintade obtained his B.Sc. and M.Sc. degrees in Electronic and Electrical Engineering from Obafemi Awolowo University, Ile-Ife, Nigeria, in 2005 and 2015 respectively. He is currently on his Ph.D. programme and lectures in the same Department with interest in Embedded Systems Design for Internet of Things (IoT) Applications. He belongs to the IoT research group of his department. His interests also include Medical Instrumentation and Low Energy Sensor Networks.

\section{Mr. KAZEEM Olaide Olawale, Obafemi Awolowo University, Ile-Ife, Nigeria}

A Masters student of Obafemi Awolowo University, Ile-Ife, Nigeria; department of Electronic and Electrical Engineering. Specializes in Control and Instrumentation. 


\title{
DEVELOPMENT OF AN INTERFACE AND CONNECTIVITY PLATFORM FOR A BASIC IoT TRAINING MODULE
}

\begin{abstract}
This paper presents a basic laboratory training module aimed at helping undergraduate students understand the interfacing and connectivity issues involved in the Internet of things (IoT). The training module uses a sequential teaching approach to draft quasi-experiments for teaching basic IoT concepts. Interfacing includes identification, embedded sensing and embedded actuating while connectivity includes wireless connectivity and web/ mobile services.
\end{abstract}

An IoT function (control and/or measurement) is first selected by users based on the physical variable of interest and the action to be carried out. The user will also select a connectivity option based on network types and transmission technologies available for communication between a sensor and/or an actuator and a gateway. The available connectivity options in this work are Bluetooth and RF. An interface is then setup based on the choices made using Arduino Pro Mini as microcontroller. Arduino Yun and a smartphone are the available gateway options depending on the connectivity option of the interface. When Bluetooth is the connectivity type on the interface, the smartphone is used as gateway while Arduino Yun serves as the gateway when RF is the connectivity option on the interface. The training module is accompanied with an instruction manual which contains instructions on the set ups and short notes on signals and systems, Analog to Digital Converters (ADC), Digital to Analog Converters (DAC), Wireless Sensor Networks (WSN), etc.

The training module was tested with 100 randomly selected students. A few students had problems setting up the interface correctly. Coding the Arduino boards was a challenge for some of the students while a few others had challenges with creating sensor nodes. Choosing the correct connectivity type to match a gateway was the most challenging for the students.

Keywords: sensor, actuator, connectivity, interface, Internet of Things.

\section{Introduction}

The Internet of Things (IoT) may be defined as the network of physical objects or "things" that are embedded with electronics, software, sensors and connectivity so that the object can have better value or provide better services by sharing resources with other objects and by exchanging data with the manufacturer, operator and/or other connected devices. A simple IoT building block is shown in Figure 1. Each object within the network is uniquely identifiable, can be accessed through a network and can be controlled using lightweight software. Though IoT is still emerging, there have been such projections that as many as 100 billion IoT devices would be interconnected by 2025 with a global economic impact of more than $\$ 11$ trillion. This is largely due to the anticipated IoT impact on agriculture, healthcare, energy management, security, etc. 


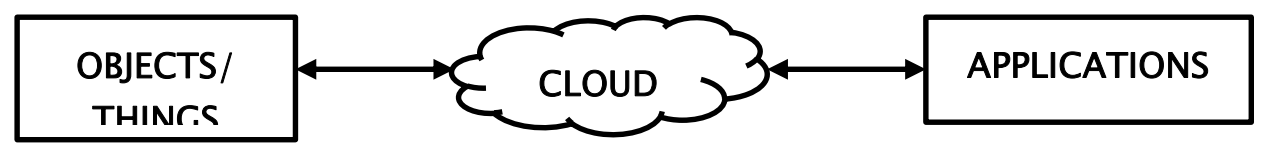

Figure 1: A simple IoT building block

IoT now commands research focus all over the world [1] and it is therefore important that academic and research institutes should enhance the teaching of basic IoT. In this work a basic laboratory module aimed at helping undergraduates understand the interfacing and connectivity issues involved in IoT is presented. Interfacing includes identification, embedded sensing and embedded actuating while connectivity includes wireless connectivity and web/ mobile services [2]. A sensor node is created using Arduino Pro Mini, temperature and humidity sensors, a relay switch actuator and LEDs, RF transceiver and a Bluetooth module. An Arduino Yun serves as the base station for the sensor nodes and also provides internet connectivity (gateway). A smart phone (running Android OS) is also used as a gateway. Web app and Android app are also created for internet and mobile connectivity respectively. Other features of the lab module include story boards as a guide for all experiments, as well as drag and drop concept for the setup when using the web app. A typical setup is shown in Figure 2.

It is expected that at the end of the experiments, students will have a clear understanding of the operation of selected sensors and actuators, interfacing issues, data presentation and connectivity types.

\section{Review}

Increase in the number of potential internet connected objects has exposed problems which cut across interfacing, connectivity, security and also optimization of connected nodes of objects. Also, in teaching IoT, apart from vendor based kits there is scarcity of educational IoT modules adapted to class lectures. The main challenge with interfacing is to make objects that are erstwhile unintelligent intelligent (or smart). Smart objects are the building blocks for the Internet of Things [3]. Capabilities of smart objects include embedded sensing, embedded actuating, embedded processing, communication and addressability, identification and localization [4]. Connectivity addresses how IoT devices connect and communicate. The Internet Architecture Board (IAB) in March 2015 released an architectural document that guides the networking of smart objects. This outline presents a framework for the following four common communication models used by IoT devices [5].

- Device-to-Device Communication Model

- Device-to-Cloud Communication Model

- Device-to-Gateway Communication Model

- Back-End Data-Sharing Communication Model

This work uses the third communication model, that is, Device-to-Gateway communication model as shown in Figure 3.

A few books on IoT [6][7][8], (just to mention a some) and several development kits that offer hardware and software for designing and building IoT devices already exist. Most of the books teach IoT in theoretical ways, while the development kits focus on vendor specific tools or other products used in creating specific IoT applications. However, there is a need to have a training 
module that focuses on teaching basic IoT concepts (especially to undergraduates) which has not been done or reported. This work, therefore, focuses on a teaching model that will help students experiment with IoT ideas through some laboratory sessions.

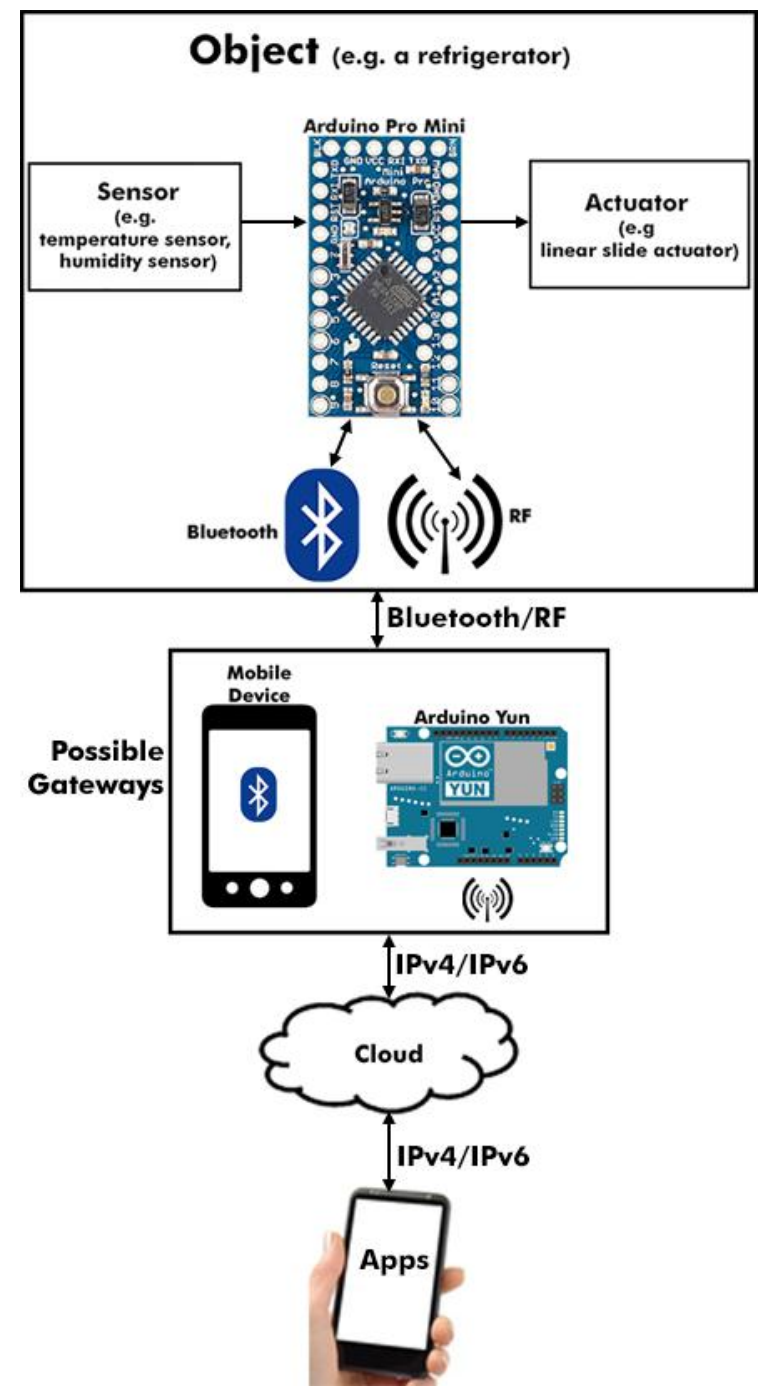

Figure 2: Schematic diagram of the setup

A number of learning models with corresponding teaching styles have been identified in engineering education [9]. These learning models include;

- Sensing and intuitive learning

- Visual and auditory learning

- Inductive and deductive learning

- Active and reflective learning

- Sequential and global learning 


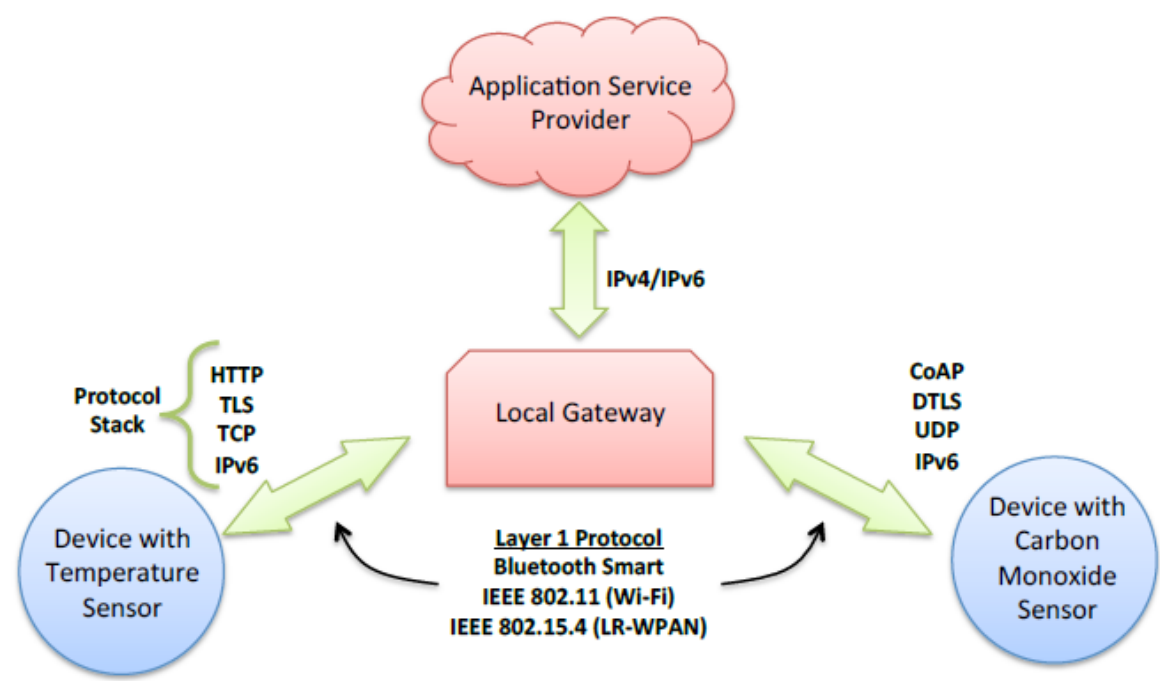

Figure 3: Example of device-to-gateway communication model [3]

This work uses the sequential teaching approach to draft quasi-experiments for teaching basic IoT concepts. The aim is to teach IoT in a progressive pattern. The teaching trend moves from an introductory level, to an intermediate stage and then finally to an advanced level. This technique ensures that students are able to follow the gradual progress of understanding the basic concepts of IoT.

\section{Understanding by Design Model (UbD)}

To ensure this proposed teaching model works, this research adopts a model for designing and evaluating. The Understanding by Design Model [10][11] is an approach which is targeted at individuals and groups who are interested in improving their skills in designing units of study. It approaches study units from a design perspective, other than as a mere pre-teaching duty. It has been proved that the model has great impact on the learners' rate of understanding [12]. The model achieves this by using a backward-design unit approach which defines and considers three components when a unit is designed for study. What are the desired results (the goal)? What is the evidence of achieving unit goal? How might these results be best achieved? With these questions, the model provides a guide to preparing an effective unit study; this paper adopts the model to evaluate the effectiveness of the proposed teaching model. Table 1 shows the answers to the UbD questions as regards designing a unit for study using the proposed teaching model.

Table 1: Designing a unit study for the proposed training module using the UbD modeling questions

\begin{tabular}{|c|l|}
\hline Question & Answer \\
\hline $\begin{array}{c}\text { 1. What are the desired results the } \\
\text { training module hopes to achieve? }\end{array}$ & $\begin{array}{l}\text { The goal of this teaching model using the } \\
\text { training module is to expose learners to the } \\
\text { vast applications and design of IoT systems. } \\
\text { The students should be able to specify the } \\
\text { certain interfaces or connectivity type to use } \\
\text { for a defined function. }\end{array}$ \\
\hline
\end{tabular}




\begin{tabular}{|c|c|}
\hline $\begin{array}{l}\text { 2. What is the evidence of achieving the } \\
\text { desired goal? }\end{array}$ & $\begin{array}{l}\text { The learner should be able to select interfaces } \\
\text { for different functions and explain why the } \\
\text { interface is selected. The learners should be } \\
\text { able to apply the connectivity RULE to } \\
\text { designing block diagrams for an IoT system. } \\
\text { The learner should be able to explain how the } \\
\text { block diagram that is designed can serve as an } \\
\text { IoT application in the real world. }\end{array}$ \\
\hline $\begin{array}{l}\text { 3. How might these results be best } \\
\text { achieved }\end{array}$ & $\begin{array}{l}\text { The learners would go through a set of } \\
\text { experiments which gradually brings them to } \\
\text { the desired result. At the end of each } \\
\text { experiment a short quiz is given to show the } \\
\text { evidence of achieving the unit goals. }\end{array}$ \\
\hline
\end{tabular}

\section{The Proposed Basic IoT Teaching Model}

This research work focused on proposing laboratory experiments that uses a generalized algorithm to determine the right interface and connectivity types when designing an IoT system because the major considerations in IoT design are interfacing and connectivity. So, students are walked through a step-by-step learning and understanding of interfacing and connectivity issues as shown in the flowchart in Figure 4.

A student will first determine the function required of the simple IoT system. This will enable him choose an appropriate sensor or actuator or even both depending on whether the function is measurement, control or both, respectively. Bluetooth or RF is then selected as the connectivity type. At this point, the student creates an interface using the sensor or actuator, a processor (in this case Arduino Pro Mini) and the connectivity type selected. A gateway is then selected. As a rule, the gateway must have the same connectivity type as the interface and must also be able to connect to the internet (a cloud service). The student finally tests his setup with a mobile app (on a smart phone) or a web app (on a personal computer) connected to the cloud over the internet.

Table 2 shows examples of applying this model to IoT designs by considering the interface and connectivity of the system.

A training module and mobile/ web app is developed to conduct each of the experiments shown in Figure 5. The students are provided with all the necessary tools including circuit diagrams for connecting peripherals to an Arduino board. The mobile app runs on an Android mobile platform. The application service employed is called Blynk and is depicted in Figure 6. A widget box is provided with all the necessary control/indicator components shown in Figure $6 \mathrm{~b}$ which is used in designing the interface of Figure 6a which displays temperature and humidity on an LCD screen. Table 3 shows the function of each component on the interface. 


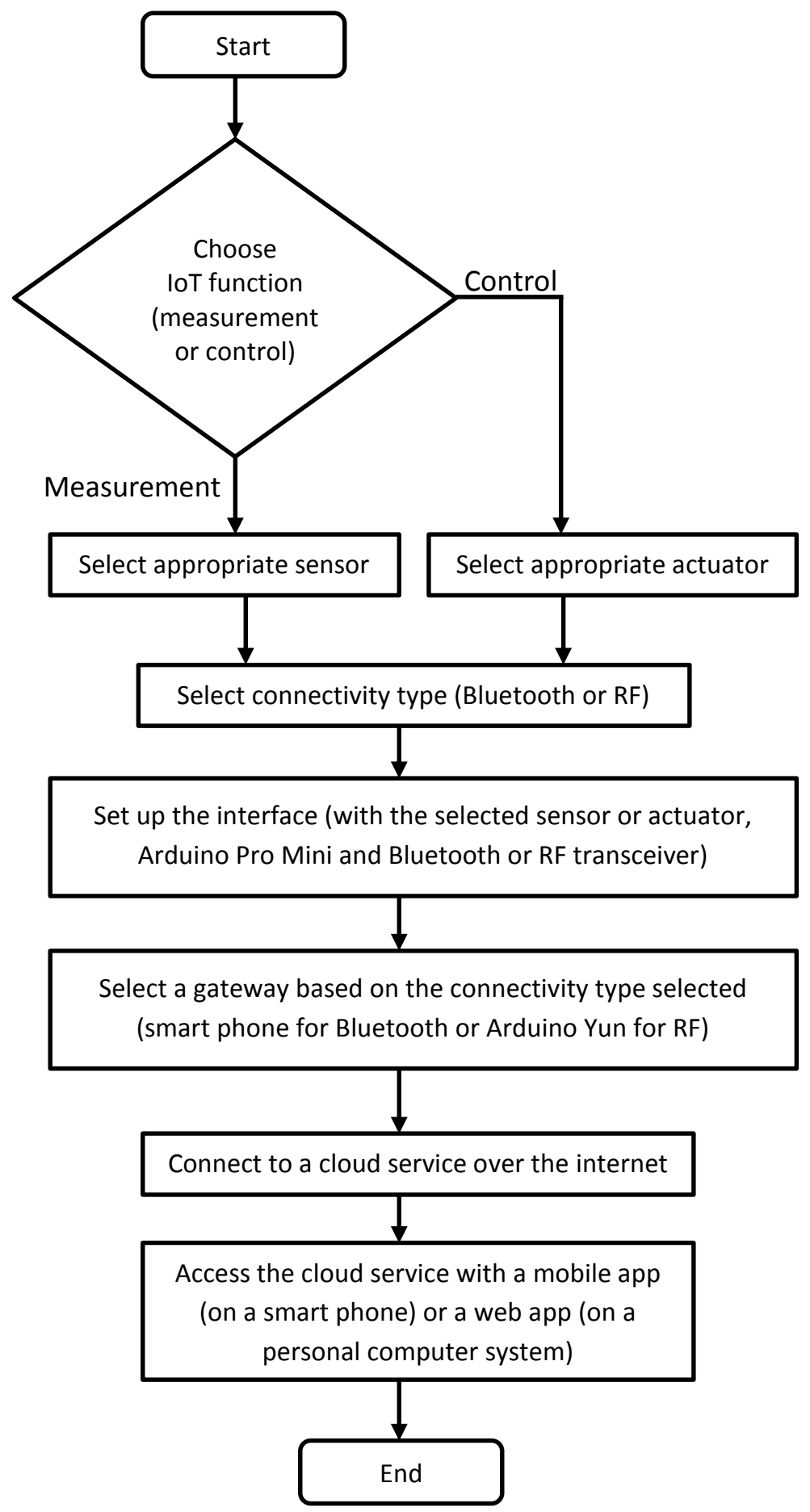

Figure 4: Flowchart showing experimental procedure

Table 2: Examples of the application of the proposed basic IoT teaching model

\begin{tabular}{|l|l|l|l|l|l|l|}
\hline Function & Sensor & Processor & $\begin{array}{l}\text { Connectivity } \\
\text { Type }\end{array}$ & Gateway & $\begin{array}{l}\text { Connectivity } \\
\text { to Cloud } \\
\text { Service }\end{array}$ & App \\
\hline
\end{tabular}




\begin{tabular}{|c|c|c|c|c|c|c|}
\hline $\begin{array}{l}\text { To monitor } \\
\text { humidity in a } \\
\text { room }\end{array}$ & $\begin{array}{l}\text { Humidity } \\
\text { sensor }\end{array}$ & $\begin{array}{l}\text { Arduino } \\
\text { Pro Mini }\end{array}$ & Bluetooth & Smart phone & Internet & $\begin{array}{l}\text { Web } \\
\text { App }\end{array}$ \\
\hline $\begin{array}{l}\text { To monitor soil } \\
\text { temperature }\end{array}$ & $\begin{array}{l}\text { Temperature } \\
\text { sensor }\end{array}$ & $\begin{array}{l}\text { Arduino } \\
\text { Pro Mini }\end{array}$ & $\begin{array}{l}\text { RF } \\
\text { Transceiver }\end{array}$ & Arduino Yun & Internet & $\begin{array}{l}\text { Mobile } \\
\text { App }\end{array}$ \\
\hline $\begin{array}{l}\text { To ensure that a } \\
\text { refrigerator door } \\
\text { is not left open } \\
\text { for more than } 20 \\
\text { seconds }\end{array}$ & $\begin{array}{l}\text { Temperature } \\
\text { and } \\
\text { humidity } \\
\text { sensors, } \\
\text { linear slide } \\
\text { actuator }\end{array}$ & $\begin{array}{l}\text { Arduino } \\
\text { Pro Mini }\end{array}$ & Bluetooth & Smart phone & Internet & $\begin{array}{l}\text { Mobile } \\
\text { App }\end{array}$ \\
\hline
\end{tabular}

\section{$\underline{\text { Experiment List }}$}

1. LED Switching over Internet

2. A/C Bulb Switching over

Internet

3. Monitoring Temperature and Humidity over Internet

4. D/C Motor Control over Internet

Figure 5: List of Experiments for the Basic IoT Training Module

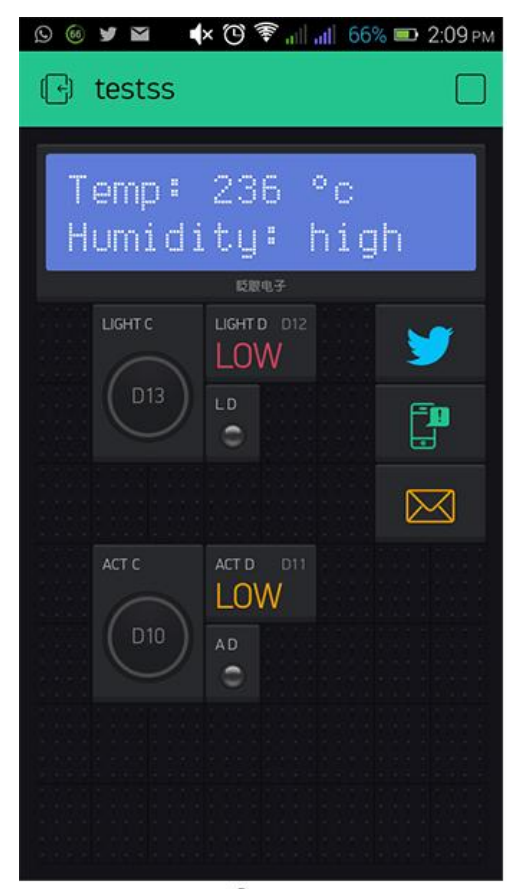

a

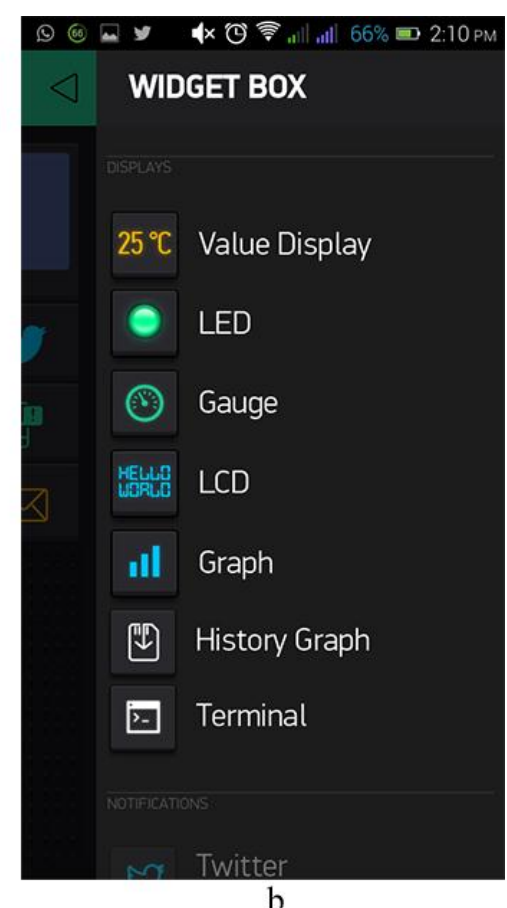

b 
Figure 6: Mobile App

Table 3: Function of each component ID

\begin{tabular}{|l|l|l|}
\hline S/No & Component ID & Component Functions \\
\hline 1. & Relay C & $\begin{array}{l}\text { Relay Control for turning } \\
\text { on/off the A/C or LED bulb. }\end{array}$ \\
\hline 2. & Motion C & $\begin{array}{l}\text { Motion Control for turning } \\
\text { on/off the dc motor }\end{array}$ \\
\hline 3. & L D & $\begin{array}{l}\text { Light Indicator for indicating } \\
\text { the A/C or LED bulb state. }\end{array}$ \\
\hline 4. & A D & $\begin{array}{l}\text { Actuator Indicator for } \\
\text { indicating the motor state. }\end{array}$ \\
\hline
\end{tabular}

At the end of each experiment students take a quiz which evaluates and gives evidence of the learning progress. This evidence corresponds to the UbD model. The web/ mobile interface for each experiment is built with a feedback indicator to ensure the control request is executed. This is required in situations where physical access to controlling device is not possible.

The experiments for the basic IoT training module are further discussed;

\section{(a) LED Switching over Internet}

The goal of this experiment is to introduce students to the basic concept of IoT using LED. Although neither a sensor nor an actuator is needed for this experiment, students are expected to identify that the IoT function required is control. For this experiment, students will be required to set up the system and independently use RF and Bluetooth as connectivity types. The students then use the mobile/ web app to test their system. They will be required to record the actual state of the LED when controlled from the app.

\section{(b) A/C Bulb Switching over Internet}

Controlling an A/C bulb is a step ahead of controlling an LED. With this, the learner understands how to manipulate alternating current devices by controlling them remotely. It also brings students to the understanding of actuators using a relay. Students must identify the IoT function as control and select a relay as the actuator for switching the bulb on and off. Students will then be required to set up the system and independently use RF and Bluetooth as connectivity types. The students then use the mobile/ web app to test their system. They will be required to record the actual state of the bulb when controlled from the app.

\section{(c) Monitoring Temperature and Humidity Remotely over Internet}

It has been discussed earlier that sensors are key parts of an IoT system. To this end, a measurement experiment that used temperature and humidity sensors is introduced to the learner. Students must identify the IoT function as measurement and select the appropriate sensors. These sensors must be correctly connected to the processor (Arduino Pro Mini) and set up must be completed by the students. Bluetooth must be used as the connectivity type and data obtained from the mobile app recorded.

\section{(d) D/C Motor Control over Internet}


This experiment concludes the basic understanding of IoT for the learner. The learner controls a dc motor over the internet. Students must recognize the IoT function as control and identify the actuator. They must set up the system correctly and test with the mobile/ web app. Motor speed will be varied on the app and compared to the actual speed of the motor.

Though students are not required develop the mobile or web apps they will be working with, they have to code the Arduino boards (Pro Mini and Yun). Templates and instruction manual are provided to help them come up to speed with coding the Arduino boards. The instruction manual also includes instructions on the set ups and short notes on signals and systems, Analog to Digital Converters (ADC), Digital to Analog Converters (DAC), Wireless Sensor Networks (WSN), etc.

\section{Testing and Results}

To test the proposed teaching model, organized laboratory sessions were carried out at the authors' University using 100 randomly sampled students. Ten groups constituting 10 students per group were used. The students used the developed lab module and apps to execute each experiment listed above. Results are presented in Figures 7a, b and c.

Figure 7a shows that most students (76 out of 100) were able to select the correct IoT function (that is, measurement or control) and setup the interface correctly. A right choice of measurement or control is necessary for a successful interface setup. Therefore, all the students that got the IoT function wrong found it difficult to set up the interface correctly. Only a very few who got the IoT function right were not able to set up the interface (mainly because they could not set up the sensor nodes successfully).

Figure $7 \mathrm{~b}$ shows that a number of students (36 out of 100) got confused with the connectivity rule that the gateway must have the same connectivity type with the connectivity type chosen for the interface. This is because there are two possible gateways (Arduino Yun and Smart phone) available for selection depending on the connectivity type defined for the interface. If the connectivity mode of the interface is Bluetooth, then a smart phone must be the gateway. When the connectivity type defined on the interface is RF, Arduino Yun is used as gateway.

The main result is shown in Figure 7c. It shows that only 51 out of 100 students were able to complete all the experiments successfully. This is largely due to the selection of a wrong gateway for the connectivity type selected as shown in Table 2. Also, a few had problems setting up the interface correctly because of a wrong choice of IoT function. Coding the Arduino boards was a challenge for some of the students while a few others had challenges with creating sensor nodes (that is, connecting the sensors and/or actuators, RF and/or Bluetooth with the microcontroller- Arduino Pro Mini). 


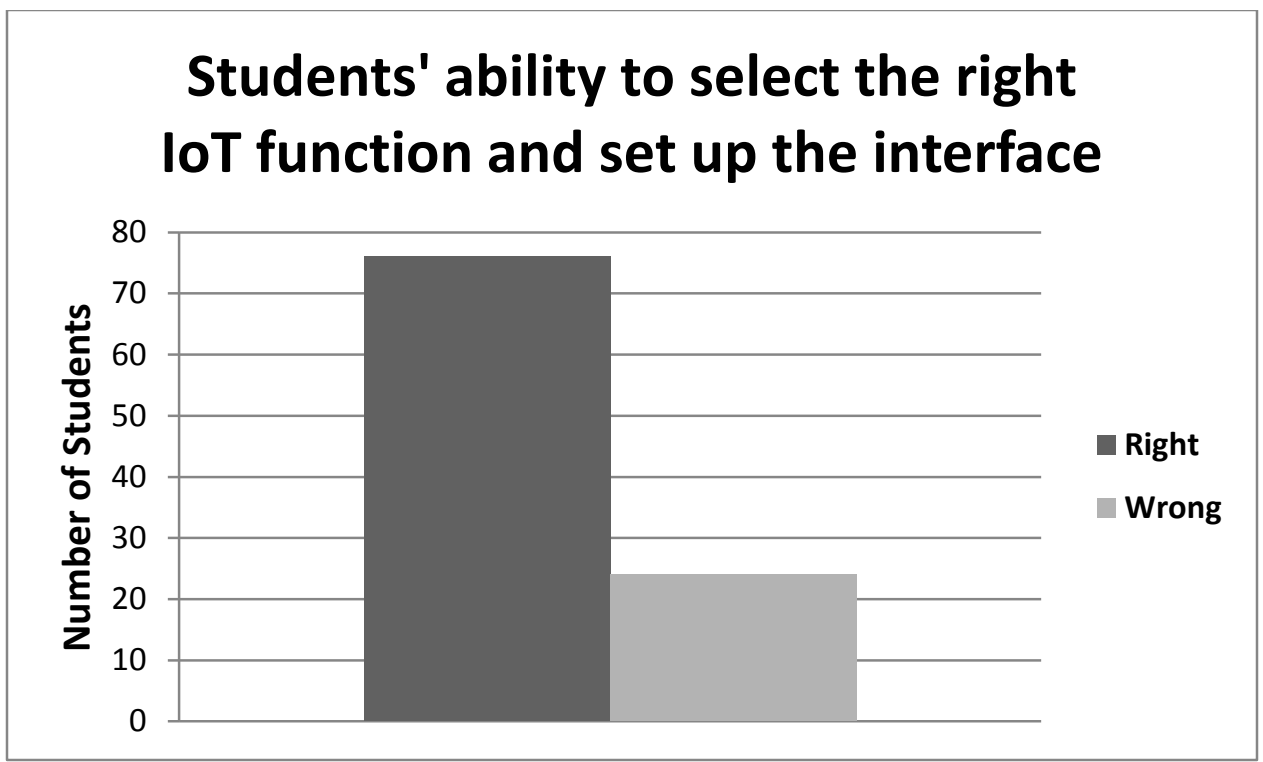

(a)

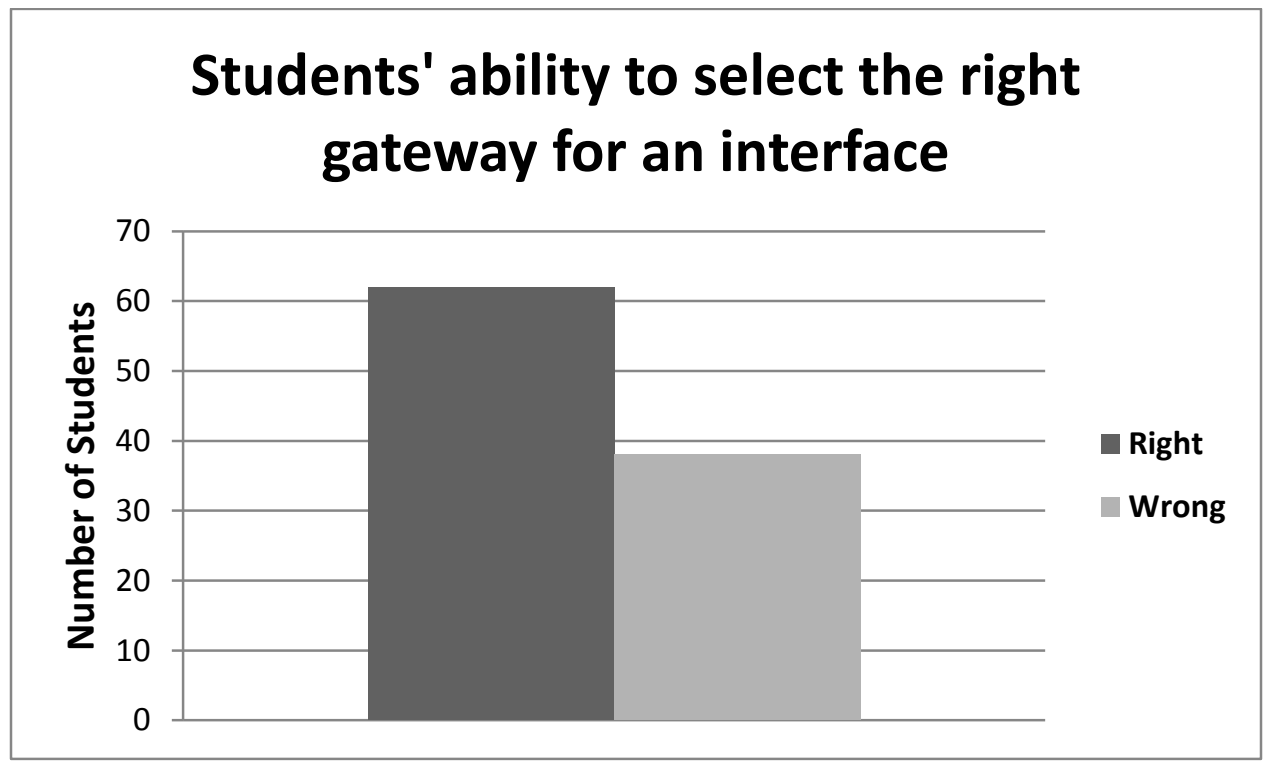

(b) 


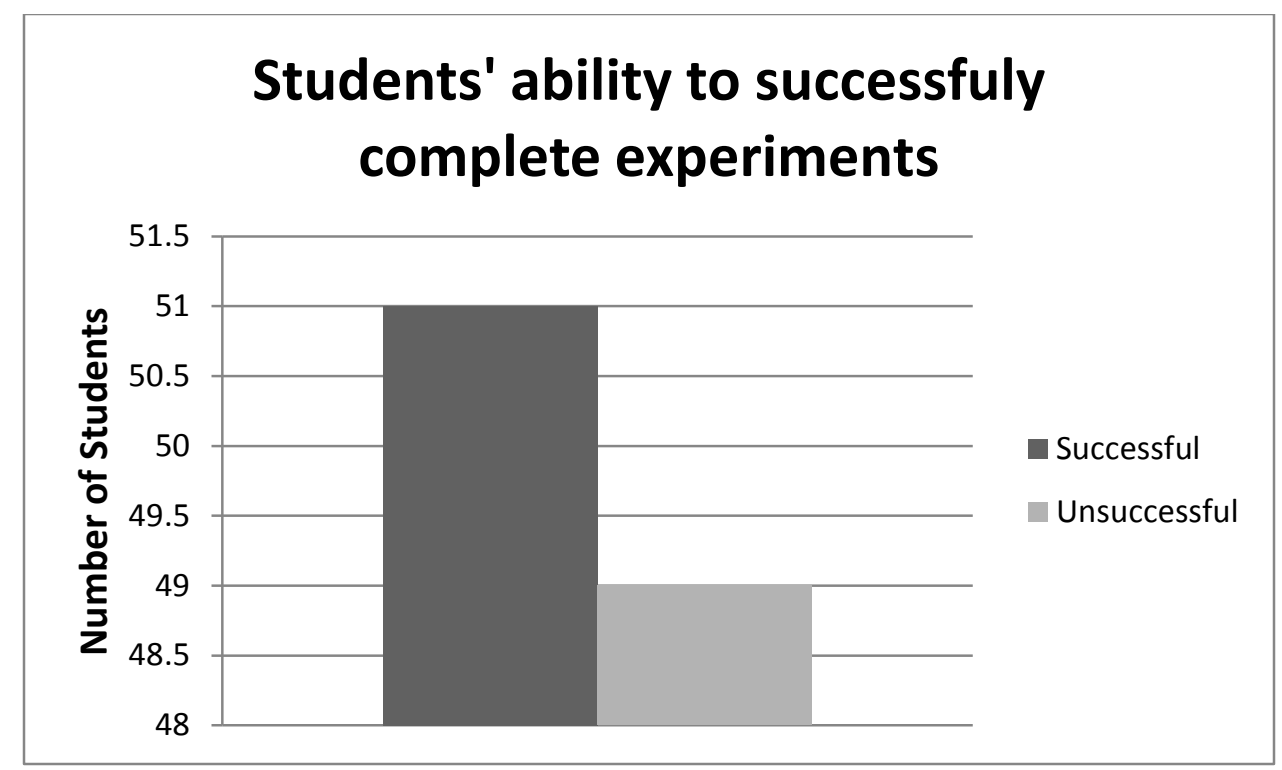

(c)

Figure 7: Results obtained from using the training module

\section{Conclusion}

The essence of teaching basic IoT concepts is for the ability of students to apply these concepts to real life applications (such as agriculture, medical, industrial, social etc.). This implies that an advanced study material is required to bring students to an application level. Based on the results presented in the previous section, the proposed IoT teaching model works to an extent and will definitely engender interest in developing IoT applications especially in developing countries where IoT applications are almost non-existing. However, for further research purposes, this can only serve as a basis for introduction to IoT and will require a follow-up model for teaching real life IoT applications.

In summary this work has been able to address interfacing and connectivity issues involved in teaching IoT. A training module has been developed which utilizes temperature and humidity sensory units, LEDs, relays and radial motor as sensors and actuators. Connectivity was tested using RF transceivers and Bluetooth. Arduino Yun and a smartphone were used as gateways.

It was also obvious that some students had problems with experiment completion because of inadequate understanding of the relevant theory. This fact will assist the teachers focus on necessary feedback to address their problems.

\section{References}

1. J. A. Stankovic. "Research Directions for the Internet of Things", IEEE Internet of Things Journal, vol. 1, no. 1, pp. 3-9, 2014. 
2. "What the Internet of Things (IoT) Needs to Become a Reality (White Paper)". NXP Semiconductors, 2014. 10 Jan. 2015 < http://www.nxp.com/files/32bit/doc/white_paper/INTOTHNGSWP.pdf >

3. G. Kortuem, D. Fitton, F. Kawsar and V. Sundramoorthy. "Smart Objects as Building Blocks for the Internet of Things", IEEE Internet Computing pp. 30-37, January/February 2010.

4. F. Mattern, C. Flörkemeier. "From the Internet of Computers to the Internet of Things", LNCS, vol. 6462, pp. $242-259,2010$.

5. K. Rose, S. Eldridge, L. Chapin. "The Internet of Things: An Overview", The Internet Society (ISOC), 2015.

6. A. McEwen \& H. Cassimally. "Designing the Internet of Things", United Kingdom: Wiley, 2014.

7. A. Bahga \& V Madisetti. "Internet of Things (A Hands-on-Approach)" ISBN: 978-0996025515, 2014.

8. $\quad$ S. Greengard. "The Internet of Things (Essential Knowledge)", USA: MIT, 2015.

9. R. M. Felder \& L. K. Silverman. "Learning and Teaching Styles in Engineering Education", Journal of Engineering Education, 78(8), 674-681, 1988.

10. G. Wiggins \& M. Jay. "The Understanding by Design Guide to Creating High-Quality Units-Association for Supervision \& Curriculum Development", Alexandria, VA : s.n., 2011.

11. J. Bruner. "The Process of Education", Cambridge, MA: Harvard University Press, 1960.

12. G. Wiggins \& J. McTighe. "Schooling by Design: Mission, Action, and Achievement", Alexandria, VA : s.n., 2007. 